\title{
Position Paper: Gamification in the Learning Process
}

\author{
https://doi.org/10.3991/ijoe.v18i01.26609 \\ Eman Najjar ${ }^{(凶)}$, Reham Salhab \\ An-Najah National University, West Bank, Palestine \\ Eman.alnajjar2010@gmail.com
}

\begin{abstract}
Recently, learning environments have transformed from traditional, lecture-based learning environments to team-based, experiential and problem-based learning to prepare learners for a more complex and collaborative world. One teaching approach that embodies these essential characteristics of learning is gamification. Gamification is the application of gamified thinking and game mechanics to solve problems and increase engagement (Çeker \& Özdam, 2017) [1]. Gamification is characterized by its ability to achieve cognitive, emotional, and behavioral effects by giving students opportunities to improve their critical thinking skills, arouse their feelings of curiosity, and increase active participation, respectively. However, considering gamification as an approach for education and learning is still a controversial subject. It is our position of this paper that as educators, we believe that gamification engages learners, motivates them to learn, satisfy their needs, and transfers knowledge by fun tasks.
\end{abstract}

Keywords—gamification, engagement, motivation

\section{Introduction}

As teachers, we are educating a generation of students who have more access to technology, media, information, and communication than any previous generation. A generation that has different learning styles that we need to address (Boudadi \& Gutiérrez-Colón, 2020) [2]. The use of gamification approach goes back to 2008's (Carlson, Harris, \& Harris, 2017) [3], where teacher's interest has increased dramatically because of the ability of educational games to increase student motivation and involvement in the learning process (Treiblmaier \& Putz, 2020) [4], which cannot be achieved by traditional educational methods and strategies. Gamification elements such as narratives, progressions, relationships, and emotions are used to engage students in learning (Zainuddin, Chu, Shujahat \& Perera, 2020) [5]. Moreover, gamification has proven to enhance cognitive, emotional, social learning outcomes and cooperative learning skills more than traditional methods "as stated in [5]". Gamification appears to be a new approach that has started to be used in a variety of disciplines to enhance and motivate learning, it incorporates fun into learning activities (Furdu, Tomozei, \& Kose, 2017) [6]. Gamification is defined as reconstructing an activity as a game, often by employing points, levels, goals, and so forth as motivational af- 
fordances (Hassan, 2017) [7]. Gamification applications do not require students to have toys, electronic devices, but only specific goals have to be achieved in a specific area, it will not replace the learning process itself, in turn it helps to make learning a more collaborative activity. "As stated in [3]".

Our position in this paper is that gamification enhances motivation and engages learners cognitively and behaviorally and emotionally which will facilitate their learning process.

Despite gamification being a relatively recent trend, the notion of bringing video game-like interfaces to the classroom is not exactly novel and under debate (Huang, Hew, \& Lo, 2019) [8]. Empirically, the majority of studies have shown more positives than negatives. "As stated in [3]". While Xi and Hamari (2019) [9], showed that learners improved their interest towards subjects that helped them learn better, some authors believed that gamification is hurting or not helping students "as stated in [6]". It has been an argued topic in general. Furdu, et al. (2017) [6], discussed that gamification is a waste of time that teaches students bad habits and values, on the other side, Çeker and Özdaml (2017) [1]. Showed that gamification is as a learning tool that allows students to be creative and learn in a different perspective.

\subsection{Gamification and motivation}

We believe that gamification influences motivation positively by offering competition, challenge, and socialization elements. Treiblmaier and Putz (2020) [4]. showed that gamification works as a moderator for the impact of intrinsic motivation for learning as it helps learners to feel pleasured, be friendly and imaginative, and selfactualized. Gamification is intrinsically motivating students because of decision making processes involved in learning; fun because goals allow student to see the direct impact of their efforts by instant feedback offered; authentic because fantasy provides a compelling background that allows students to experiment with skills without suffering the consequences of failure in real life; teaching students self-reliance because feedback is offered; social because it allows students to share experiences and build bonds "as stated in [4]". We do support gamification since extrinsic motivation is often associated with being facilitated mainly by the desire to acquire rewards, points, ladderbords and avoid punishments using external incentives "as stated in [9]".

Both intrinsic and extrinsic motivation play crucial roles in promoting students' learning engagement through gamification that targets three basic needs: competence, autonomy, and relatedness "as stated in [8]".

\subsection{Gamification and engagement}

We support that integration of gamification elements into learning activities to engage learners cognitively, behaviorally, and socially. Several studies (Zainuddin et al., 2020; Amado, \& Roleda, 2019; Alsawaier, 2018) [5], [10], [11]. supported this position that gamification increases student engagement and has positive effects on students' behavioral, emotional, and cognitive engagement by the features it offers like: persistence, time-on-task, flow, immersion, and commitment. 
Amado and Roleda (2019) [10]. found that behavioral engagement involved in gamification as it correlates to behavioral theory, rewards and reinforcements that present in a certain game, rewards are used to reinforce the learning of the desired behavior.

Cognitive engagement can be likened to immersion of students; students are being absorbed and involved in tasks during gamification. Huang et al. (2019) [10]. discussed that students' brains are processing information intensely, they are thinking, exploring, and they are aware of their own learning. Gamification engaged students emotionally by powerful game narratives, achieving goals, enjoying the feeling when they face a challenge and overcome it; joy of accomplishment and encouraging a sense of community and teamwork as stated in [11]. Alsawaier (2018) \& Hassan (2017) [11]. [7]. confirmed that gamification aims to promote motivation and longterm engagement in learning as shown in the Figure 1.

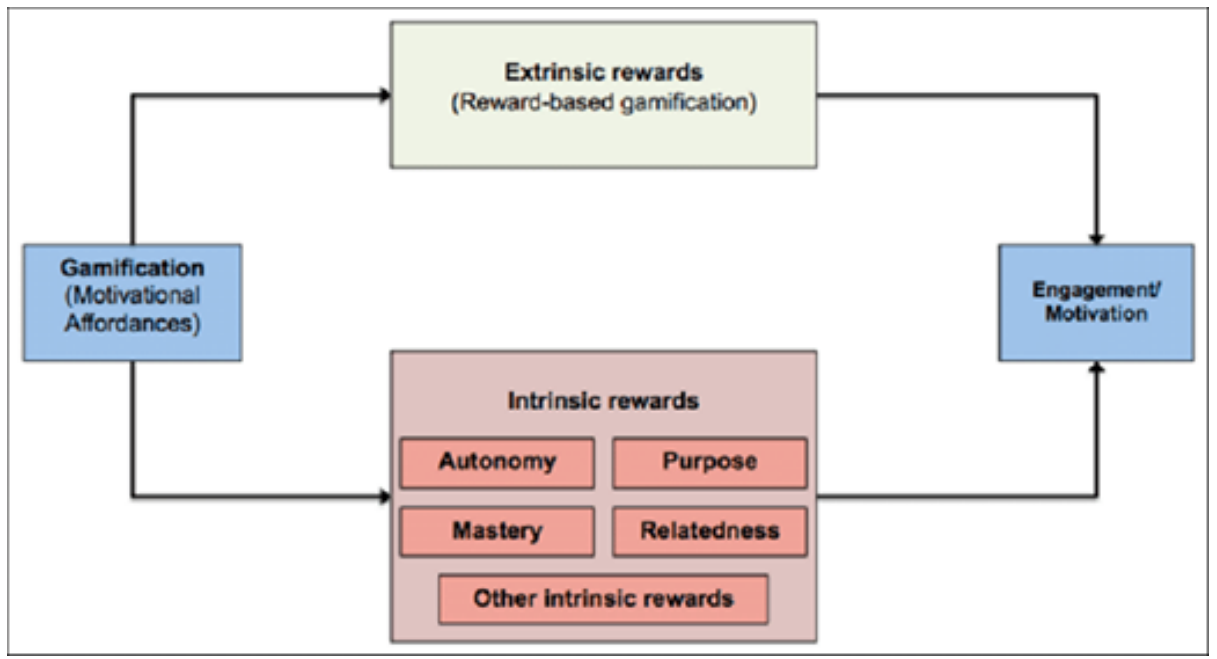

Fig. 1. Influence of gamification on motivation and engagement.2107

Note. Influence of gamification on motivation and engagement, is shown that gamification aims to promote motivation and long-term engagement in learning. From "Governments should play games: Towards a framework for the gamification of civic engagement platforms", by L. Hassan, 2017, Simulation \& Gaming, 48(2), p. 256. (https://doi.org/10.1177/1046878116683581) Copyright 2016 by the ISAGE.

Gamification does not achieve the desired results, especially with regard to the engagement of students, engagement fades as students feel bored, frustrated, as gamification here did not improve the outcomes of the educational process, (Furdu, et al., 2017). Nonetheless, these negative emotions contributed to the student's drive to always perform better (Amado \& Roleda, 2019) [10]. Çeker and Özdaml (2017) [1]. opposed what was mentioned about lack of engagement gamification offers, they proved that gamification is entertaining, transforming hard work procedures to more fun tasks, helping to solve problems and offering immediate feedback to students to 
monitor student's progress by learning analytics. Moreover, they clarified that the feelings of students during gamification is determined by the goal of game use and its effect it has on students.

Another argument against gamification is loss of performance, feeling indifferent; neither enjoyable nor boring, gamification did not impact learners' motivation and engagement, preferring traditional methods over gamed ones, gamification did not improve learners' gain of knowledge, and it did not exert any impact on cognition and performance (Toda, Valle, \& Isotani, 2017) [12]. In their study, Boudadi and Gutiérrez-Colón (2020) [2]. opposed these arguments by clarifying how using gamification boosts motivation by using points, rewards, focuses, makes students more attentive, and increases competition. Several studies. Moreover, Carlson et al. (2017) [3]. showed when incorporating fun into game activities, this helps to enhance motivation ability and enhance interaction, which lead to positive behavioral outcomes by practicing real life situations and challenges.

On the other hand, the evaluation of gamification world market is an indication of its positive effect, as in 2017 , the global gaming market was generally valued at $\$$ 2.17 billion and estimated to reach $\$ 19.39$ billion by 2023 as stated in [9].

\section{Conclusion}

Gamification is an effective approach in individualizing learning where it motivates and engages students differently. We have positioned our-selves in favor of gamification as it is one of the modern trends in educational technology, it helps students to interact and be more engaged emotionally, cognitively, and behaviorally with educational materials and with other learners meaningfully in educational activities, which increases the student's ability to be creative and satisfy their emotional and social needs such as freedom, security, leadership, and self-actualization.

We firmly support application of gamification in a pedagogical context provides some remedy for many students who find themselves alienated by the traditional schooling system. Moreover, we would like to encourage all educational institutions to apply gamification in early levels like first grades, so they get used to gamification since they spend a lot of time interacting with the virtual world. We would also propose to increase students' awareness of the importance of using gamification through seminars and student workshops, taking into consideration the age and psychological characteristics of learners. As a result, we expect teachers to follow this change and focus on the new generation needs through incorporating gamification approach with traditional digital curriculum and focus on learning analytics to optimize learning for their students.

\section{$3 \quad$ References}

[1] Çeker, E., \& Özdaml, F. (2017). What" Gamification" Is and What It's Not. European Journal of Contemporary Education, 6(2), 221-228. https://doi.org/10.13187/ejced.2017. $\underline{2.221}$ 
[2] Boudadi, N. A., \& Gutiérrez-Colón, M. (2020). Effect of Gamification on students' motivation and learning achievement in Second Language Acquisition within higher education: A literature review 2011-2019. The EuroCALL Review, 28(1), 57-69. https://doi.org/ 10.4995/eurocall.2020.12974

[3] Carlson, J., Harris, R. B., \& Harris, K. (2017). Coin counter: Gamification for classroom management. Information Systems Education Journal, 15(5), 4. Retrieved from: http:// isedj.org/2017-15/n5/ISEDJv15n5p4.html

[4] Treiblmaier, H., \& Putz, L. M. (2020). Gamification as a moderator for the impact of intrinsic motivation: Findings from a multigroup field experiment. Learning and Motivation, 71, 101655. https://doi.org/10.1016/j.lmot.2020.101655

[5] Zainuddin, Z., Chu, S. K. W., Shujahat, M., \& Perera, C. J. (2020). The impact of gamification on learning and instruction: A systematic review of empirical evidence. Educational Research Review, 100326. https://doi.org/10.1016/j.edurev.2020.100326

[6] Furdu, I., Tomozei, C., \& Kose, U. (2017). Pros and cons gamification and gaming in classroom. arXiv preprint arXiv:1708.09337. Retrieved from: https://arxiv.org/ftp/arxiv/ papers /1708/1708.09337.pdf

[7] Hassan, L. (2017). Governments should play games: Towards a framework for the gamification of civic engagement platforms. Simulation \& Gaming, 48(2), 249-267. https://doi.org/10.1177/1046878116683581

[8] Huang, B., Hew, K. F., \& Lo, C. K. (2019). Investigating the effects of gamificationenhanced flipped learning on undergraduate students' behavioral and cognitive engagement. Interactive Learning Environments, 27(8), 1106-1126. https://doi.org/10.1080/ 10494820.2018 .1495653

[9] Xi, N., \& Hamari, J. (2019). Does gamification satisfy needs? A study on the relationship between gamification features and intrinsic need satisfaction. International Journal of Information Management, 46, 210-221. https://doi.org/10.1016/j.ijinfomgt.2018.12.002

[10] Amado, C., \& Roleda, L. (2019). Student Engagement in a Gamified Physics Course. Proceedings of the International Conference on Future of Education, 2(1), 85-95. https://doi.org/10.17501/26307413.2019.2109

[11] Alsawaier, R. S. (2018). The effect of gamification on motivation and engagement. The International Journal of Information and Learning Technology, 53(1), 56-79. https://doi.org/ 10.1108/IJILT-02-2017-0009

[12] Toda, A. M., Valle, P. H., \& Isotani, S. (2017). The dark side of gamification: An overview of negative effects of gamification in education. In Cristea, A., Bittencourt, I., \& Lima, F., (Eds.), Higher Education for All. From Challenges to Novel Technology-Enhanced Solutions, (832),143-156. Springer, Cham, Switzerland. https://doi.org/10.1007/978-3319-97934-2_9

\section{Authors}

Eman Najjar is manager of the research department in the (NIET) National Institution for Educational Training in Palestine, a PhD candidate from (ANNU), specialized in teaching and learning. Eman worked as a science teacher for six years, and as a training supervisor for six years. She has published several research in international journals, presented others in national and international conferences.

Reham Salhab is PhD candidate at An Najah National University (ANNU). Currently she is a lecturer in Educational Technology department at Khadoorie University 
in (PTUK). She has published articles on the effect of Interactive smart board on preservice teachers in a microteaching environment and implementing Moodle at PTUK. Her main area of interest is e-learning, educational technology, teaching and learning, professional development, and curriculum development (Email: r.salhab@ptuk. edu.ps).

Article submitted 2021-08-30. Resubmitted 2021-10-05. Final acceptance 2021-10-08. Final version published as submitted by the authors. 